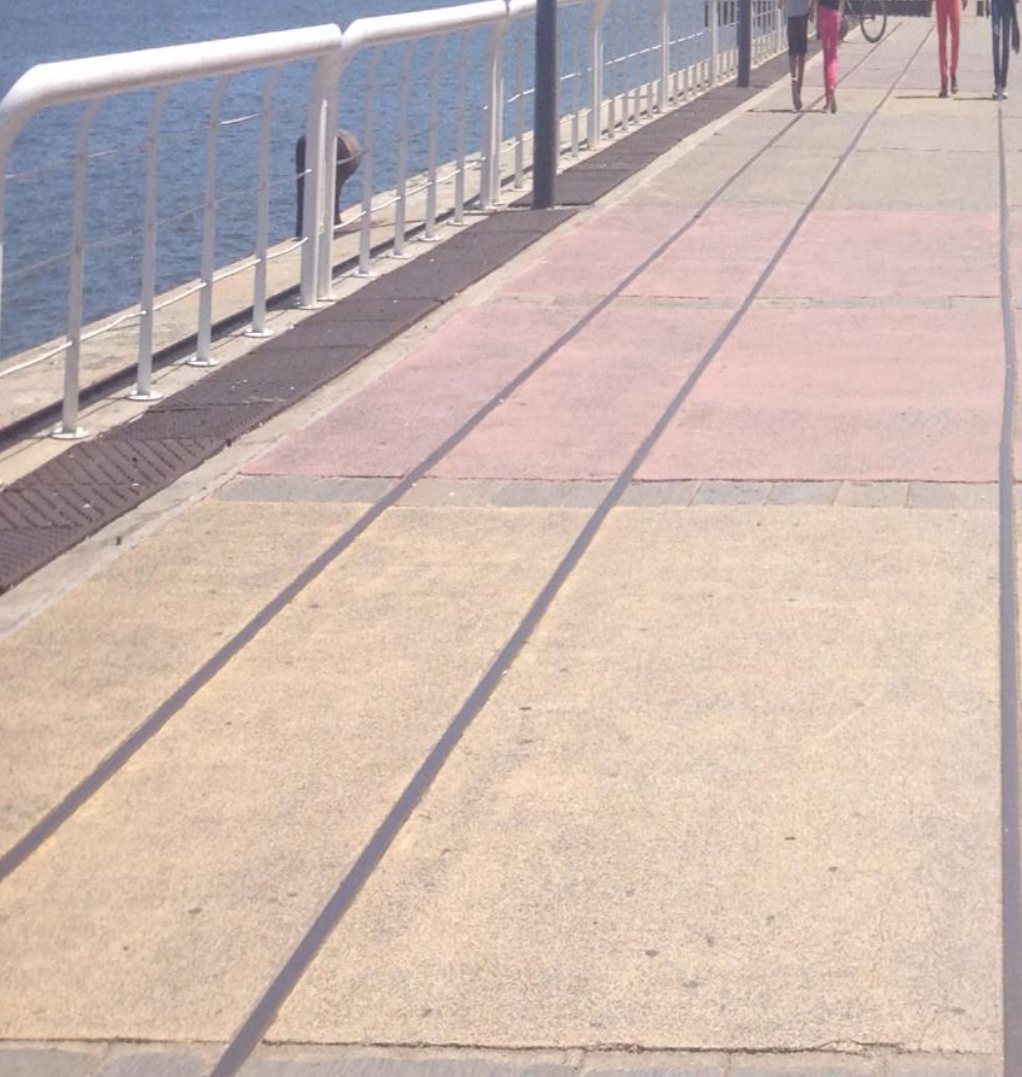

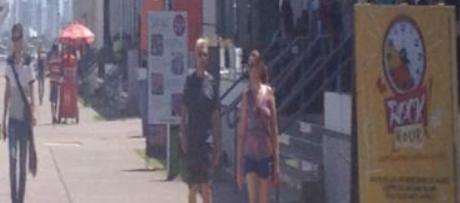

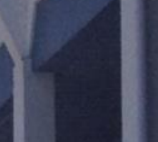




\title{
Lazer e turismo LGBT em Brasília/DF sob a perspectiva da hospitalidade
}

\author{
LEISURE AND LGBT TOURISM IN BRASILIA / DF FROM THE PERSPECTIVE OF HOSPITALITY
}

\author{
Agatha Rita Doroteia Tavares Guerra ${ }^{1}$ \\ Lívia Cristina Barros da Silva Wiesinieski \\ lara Lúcia Gomes Brasileiro ${ }^{3}$
}

\begin{abstract}
Resumo: O consumo e o turismo para o segmento de Lésbicas, Gays, Bissexuais, Travestis, Transexuais e Transgêneros (LGBT) movimenta o mercado brasileiro. Trata-se de um negócio atual e oportuno, pois esse público demanda uma participação expressiva ano após ano no mercado mundial, tanto em serviços turísticos especializados (hotéis, cruzeiros, agências de viagens) quanto em lazer, entretenimento (bares, restaurantes, baladas, saunas) e consumo de bens materiais (lojas de roupas, móveis). Nesse sentido, esse segmento do turismo tem se afirmado como uma possibilidade econômica capaz de gerar lucros significativos. Este trabalho tem como objetivo analisar, a partir de revisão bibliográfica e de textos midiáticos, a oferta de lazer na cidade de Brasília e as possibilidades do turismo para o público LGBT na perspectiva da hospitalidade. Na capital do Brasil, o público homossexual é um segmento ávido por entretenimento e por cultura; possui, em sua maioria, nível de escolaridade e remuneração mais elevado que a média, consome bastante, é muito exigente, bem informado, gosta de praticidade; em sua maioria, não possui filhos, o que torna seus gastos fixos bem menores se comparados aos de casais heterossexuais. Essas condições, somadas ao fato de Brasília ser uma cidade considerada gay friendly, certamente se caracterizam em boas perspectivas de negócios no setor do turismo.

Palavras chave: Turismo. LGBT. Hospitalidade. Lazer. Brasília/DF
\end{abstract}

Abstract: Consumption and tourism for the segment of Lesbian, Gay, Bisexual, Transvestite, Transsexual and Transgender (LGBT) moves the Brazilian market. This is a current and favourable business, as this public demands a significant participation year after year in the world market, both in specialized tourist services (hotels, cruises, travel agencies) as in leisure, entertainment (bars, restaurants, ballads, saunas) and consumption of material goods (clothing stores, furniture). In this sense, this segmentation of tourism has affirmed itself as an economic possibility capable of generating significant profits. This work aims to analyze, from a bibliographical review and media texts, the leisure offer in the city of Brasilia and the possibilities of tourism for the LGBT public in the perspective of hospitality. In the Brazil capital, the homosexual public is a segment eager for entertainment and culture; most of the people have higher levels of educational and remuneration than average; this public consumes and demands a lot, is well informed, likes practicality; in the majority, does not have children, what makes their fixed expenses much smaller when compared to the one of heterosexual couples. These conditions, alied with the fact that Brasilia is a city considered to be gay friendly, certainly characterize good business prospects in the tourism sector.

Keywords: Tourism. LGBT. Hospitality. Leisure. Brasilia

INTRODUÇÃO

No Brasil, nas últimas décadas o movimento de lésbicas, gays, bissexuais, travestis e transexuais (LGBT), tem conseguido visibilidade e conquistado alguns direitos básicos para o

\footnotetext{
${ }^{1}$ Secretária Executiva da Universidade de Brasília. Graduada em Letras e Especialista em Gestão e Marketing do Turismo ambas pela Universidade de Brasília. Mestre em Turismo pela já referida instituição (2015). Atualmente participa do Grupo de Estudos e Pesquisa sobre Gênero e Interdisciplinaridades. E-mail: agatha@unb.br

${ }^{2}$ Mestre em Turismo pela UnB(2015). Especialista em Gestão de Negócios em Turismo pela UnB (2009). Graduada em Turismo pela UFOP (2008). E-mail: liviabsw@gmil.com

3 Professora Adjunto da Universidade de Brasília, e pesquisadora no Centro de Excelência em Turismo. Graduada em Ciências Biológicas pela Universidade de Brasília, Mestre e Doutora em Ciências pela Universidade de São Paulo (1980). Email: ibrasileiro@unb.br
} 
exercício pleno da cidadania, embora essa visibilidade não pressuponha respeito ou condicione o fim do preconceito para com essa comunidade, que continua sendo alvo de discriminação.

Um avanço social significativo alcançado pela comunidade homossexual ocorreu em 05 de maio de 2011, quando o Supremo Tribunal Federal (STF) reconheceu a união estável (civil) entre casais do mesmo sexo, em uma decisão histórica. Conforme esclarece Dias (2012) "a partir desta decisão, nada mais, quer conviç̧ões de ordem subjetiva ou religiosa podem servir de justificativa para o juiz deixar de atribuir efeitos jurídicos aos vínculos formados por pessoas do mesmo sexo" (p. 31). Em maio de 2013, uma decisão do Conselho Nacional de Justiça (CNJ), deu acesso ao casamento civil para casais homossexuais, bem como obrigava os cartórios a aceitar os pedidos de conversão de uniões estáveis em casamentos. Nesse contexto, o país passa a figurar entre as nações que, há anos, já concederam esses direitos para casais homoafetivos. Uma conquista judicial de relevante importância para essa comunidade.

Em face destes avanços, a sociedade começa a ter outro olhar, mais brando, com a diversidade sexual. Apesar de ainda existir preconceito, como afirma Dias (2004) “A sociedade que se proclama defensora da igualdade é a mesma que ainda mantém uma posição discriminatória nas questões da sexualidade. Nítida é a rejeição à livre orientação sexual” (p. 51). Entretanto, esses indivíduos, continuam a lutar por direitos iguais e ao saírem da clandestinidade e constituírem novas formas de famílias, despertaram a atenção de diversos tipos de investidores que vislumbraram lucrar financeiramente com atrativos, entretenimentos, lazer, turismo, consumo, entre outros, voltados para atender esse público. Empresários começaram a dar maior atenção a esse nicho, visando prover particularidades específicas desse público. Nesse contexto, Dias (2012) enfatiza que:

Neste novo século, menores restrições pesam sobre os homossexuais, cedendo a intolerância a uma atitude de maior compreensão. Posturas predominantemente negativas são contestadas. Desmascaram-se falsos preconceitos e errôneos pressupostos estigmatizantes. (p.40).

Em função dessa visibilidade, no Brasil, o setor de turismo começa a voltar sua atenção para esses indivíduos. Brasília, a capital-monumento é uma cidade direcionada principalmente para o turismo de negócios, cívico e de eventos (Contaifer, 2014), mas que necessita diversificar para atrair outras clientelas, entre elas a LGBT.

Cientes da demanda crescente desse nicho e atentos aos bons resultados mundiais obtidos com esse público, alguns empresários de Brasília do setor de bares, hotelaria, casas noturnas, restaurantes, agências de turismo, boates, começam a investir em produtos e serviços destinados a receber esse público ávido por entretenimento que, segundo informa Bonfanti (2011), "Eles fazem parte de um grupo que está em busca, quase sempre, de produtos diferenciados e de qualidade. $\mathrm{E}$ 
compram, geralmente, mais que o restante da população. A depender do segmento, gastam o dobro da média dos consumidores" (p. 19) O Governo do Distrito Federal acena investir em ações necessárias em prol de uma maior aceitação e respeito à diversidade, conforme constataram, em reportagem, Amorim e Vasconcelos (2012). A evolução dos tempos tem a capacidade de alterar e até de corrigir injustiças sociais históricas, principalmente para com a população de homossexuais.

A oferta de lazer e os desafios da hospitalidade em Brasília voltados ao público LGBT, como um potencial atrativo turístico para o segmento, demandam investimentos de empresários locais, que, de acordo com a mídia, estão atentos aos movimentos desse nicho de mercado, e têm demonstrado interesse na conquista desse filão. Segundo dados apontados por Campbell (2014) "O Distrito Federal tem a maior taxa de relações gays registradas em cartório no país e um dos menores índices nacionais de crimes homofóbicos" (p. 29). O que, a princípio, pode ser considerado como um local receptivo, hospitaleiro para esses indivíduos.

Deve-se destacar que "A homossexualidade experimentou, ao longo da história da humanidade, diversos altos e baixos. De comportamento absolutamente natural, passou a ser pecado e até mesmo crime. Até hoje, o assunto provoca forte debate" (Oliveira, 2013).

A comunidade LGBT, na última década tem crescido e alcançado visibilidade, principalmente nos produtos midiáticos, os quais auxiliam muito na construção do entendimento da realidade social desses indivíduos. Essa visibilidade - que, como já dito, não traduz respeito ou o fim do preconceito oportunizou aos homossexuais, por meio de ações efetivas, alcançar gradativamente conquistas de alguns direitos básicos para o exercício pleno da cidadania.

Neste contexto, surge a transformação desse público em verdadeiros nichos de mercado, entre eles o do turismo. O setor de viagens e turismo passou, assim, a ter mais um segmento de entretenimento voltado para essas pessoas. Muitos ainda se questionam acerca desse tipo de turismo segmentado para homossexuais, sob a alegação de que, ao se direcionar um produto para uma minoria, estar-se-ia reforçando uma atitude preconceituosa. Entretanto, no entendimento de Trevisan (2006) deve-se cogitar a possibilidade de existir diversos tipos de turismo que privilegiem interesses de grupos distintos, e o autor afirma que, em relação ao público LGBT, "Trata-se de necessidades específicas que não podem esperar [...] que a sociedade aceite sua vocação para a diversidade e, assim, cumpra seu papel de democracia pluralista, inclusive no turismo" (Trevisan, 2006).

Os turistas LGBT, em sua maioria, conforme apontam pesquisas anteriores (Oliveira, 2002; Reinaudo \& Bacellar, 2008), possuem alto nível de escolaridade e remuneração elevada, quando comparado com a média das outras pessoas. Consomem bastante, são exigentes, bem informados e, 
na maioria das vezes, não tem filhos, fazendo com que a renda do casal homossexual seja dobrada em relação aos casais convencionais.

Diante disso, no presente artigo analisa-se, a partir de revisão bibliográfica e de textos midiáticos, a oferta de lazer na cidade de Brasília e a possibilidade do turismo para o público LGBT, na perspectiva da hospitalidade.

\section{TURISMO E HOMOSSEXUALIDADE}

Existem vários conceitos acerca do turismo. Alguns autores o caracterizam sob o aspecto econômico e sociológico, outros como uma indústria ou fenômeno (Molina, 2005). Em um sentido mais amplo, Moesch (2002) afirma que:

O turismo é uma combinação complexa de inter-relacionamentos entre produção e serviços, em cuja composição integram-se uma prática social com base cultural, com herança histórica, a um meio ambiente diverso, cartografia natural, relações sociais de hospitalidade, troca de informações interculturais. O somatório desta dinâmica sociocultural gera um fenômeno, recheado de objetividade/subjetividade, consumido por milhões de pessoas, como síntese: um produto turístico. (p.9)

No entendimento de Krippendorf (2003) "O turismo funciona como terapia da sociedade, válvula que faz manter o funcionamento do mundo de todos os dias. Ele exerce um efeito estabilizador não apenas sobre o indivíduo, mas também sobre toda a sociedade e a economia." Nesse contexto, o indivíduo passa a ter necessidade do lazer, da viagem para o descanso merecido. Enquanto Molina (2005) aponta que "As grandes transformações sofridas pelas diferentes sociedades humanas influenciaram notavelmente a conceituação e a prática do turismo." Assim, pode-se afirmar que o turismo vem se adequando às necessidades da sociedade e de seus respectivos segmentos. Viajar tornou-se um fato inerente ao ser humano principalmente a partir dos tempos modernos.

Considerando-se que a homossexualidade é tão antiga quanto a heterossexualidade; que desde os primórdios dos tempos o ser humano se locomove de um lado ao outro, a princípio, por necessidade de sobrevivência e que durante as antigas civilizações greco-romanas realizavam-se viagens motivadas pelas conquistas territoriais, religiosas, culturais entre outras, tais deslocamentos podem ser classificados como uma prática de turismo, grosso modo, similar ao existentes atualmente (Guerra, 2002). Nesse sentido, pressupõe-se que pessoas homossexuais já participavam dessas excursões. Nota-se que durante essas civilizações, as relações sexuais entre iguais eram aceitas socialmente, entretanto existiam leis rígidas para punir os excessos (Oliveira, 2013). 
A invisibilidade histórica das pessoas homossexuais nunca ocasionou despertar para a questão de que essas pessoas sempre estiveram envolvidas com viagens, logo com o turismo, de um modo geral (Trevisan, 2006). Com as mudanças ocorridas no final do século XX em virtude das conquistas e, consequentemente, do ganho de visibilidade de lésbicas, gays, bissexuais, travestis, transexuais e transgêneros, o mercado turístico passou a olhar esses indivíduos como potenciais clientes. Ao se questionar porque homossexuais viajam tanto desde a antiguidade, Trevisan (2006) aponta que:

[...] ocorre uma necessidade premente de conhecer o mundo. A tendência é que homossexuais abandonem os lugares mais inóspitos e agressivos, inclusive suas cidades de origens, para "procurar o seu lugar", movidos pelo desejo de se libertar. Daí um certo pendor andarilho que pode ser associado à vivência homossexual em nossas sociedades." (p. 144).

Em face disso, não podemos deixar de considerar que o grupo homossexual constitui um importante nicho para o mercado turístico. Trigo (2009) observa que a partir dos avanços de pesquisas acerca da sexualidade como da cultura em geral, o prazer dos indivíduos heterossexuais ou homossexuais deixou de ser relacionado à culpa e pecado. Para esse autor, tanto a aceitação da homossexualidade quanto o advento do turismo de massa, são questões bastante atuais em nossa civilização ocidental. Nesse sentido, Trigo (2009) entende que: "Sendo a liberdade sexual e o turismo de massa fenômenos igualmente recentes e frutos de possibilidades de vivência do prazer em campos cada vez mais amplos, é natural que existam conexões mais íntimas entre sexo, lazer, turismo e hospitalidade e entretenimento" (p. 142). Na contemporaneidade, o movimento LGBT vivencia um momento de avanços e conquistas, e como observou Guerra (2013) "O reconhecimento de casais homossexuais como uma família levou empresários e governos a ter outra percepção desse segmento e sinalizar favoravelmente no sentido de apostar nesse público e investir em entretenimento, lazer e turismo inclusivo" (p. 134).

A diversidade sexual compreende uma multiplicidade de expressões sexuais humanas que, em geral, divergem das normas heterossexuais vigentes na sociedade. No entendimento de Silva Junior (2014) "A diversidade sexual é um desdobramento da diversidade que integra a condição humana, manifestando-se através das orientações afetivo-sexuais e das diversas identidades de gênero". Essa questão do amor entre iguais e da diversidade sexual não é atual nem tão pouco se trata de modismo. Sua prática é tão antiga e já foi, inclusive, pensada e discutida filosoficamente na Grécia clássica por influentes filósofos como Platão e Sócrates. Nesse aspecto, no livro "O Banquete", Platão trava um debate com outros pensadores da época acerca do elogio ao amor, de suas várias formas, além das sexualidades dos seres humanos. Para Platão (1999), havia três sexos: homens, 
mulheres e andróginos (pessoas metade homem, metade mulher). Assim, esse filósofo descreve como seriam os três sexos:

Com efeito, nossa natureza outrora não era a mesma que de agora, mas diferente. Em primeiro lugar, três eram os gêneros da humanidade, não como agora, o masculino e o feminino, mas também havia a mais um terceiro, comum a estes dois, do qual resta agora um nome, desaparecida a coisa; andrógino era então um gênero distinto, tanto na forma como no nome comum aos dois, ao masculino e ao feminino [...] (p.125-126).

Existem diversos conceitos e atitudes acerca da homossexualidade que foram largamente aceitos em determinadas épocas. Entretanto, os anos e o avanço da civilização se encarregaram de abandoná-los ao passado, e que, de uma maneira geral, só surgem na atualidade como história. Embora em muitas ocasiões, contrariando os avanços conquistados por homossexuais, algumas práticas e crenças ressurjam sob o estigma daquilo que não é natural, como o amor entre iguais. No entendimento de Prado e Machado (2008), "As homossexualidades estiveram presentes no mundo de formas tão distintas quanto à própria organização cultural e moral na história das sociedades." (Prado \& Machado, 2008).

De acordo com Mott (2003), Simões e Facchini (2008), o termo homossexual foi utilizado pela primeira vez em 1869, pelo húngaro Karl-Maria Benkert, que era jornalista e memorialista, em folhetos onde esse jornalista se manifestava contra a lei prussiana que punia a sodomia masculina. Mas para Foucault (2007), a data natalícia da utilização da palavra homossexualidade, como sendo uma categoria psicológica, psiquiátrica e médica, ocorreu a partir do artigo do médico psiquiatra e neurologista alemão Carl Friedrich Otto Westphal, em 1870. No entendimento de Foucault (2007), “A homossexualidade apareceu como uma das figuras da sexualidade quando foi transferida, da prática da sodomia, para uma espécie de androgenia interior, um hermafroditismo da alma. O Sodomita era um reincidente, agora o homossexual é uma espécie" (Foucault, 2007). Controvérsias à parte, o fato é que essa expressão continua a ser usada na contemporaneidade, não mais como sendo uma patologia sexual, grafada como homossexualismo (ismo, de origem grega que significa doença), mas sim como estilo de comportamento sexual, ou seja, homossexualidade.

As questões do binarismo de gêneros são bastante antigas, assim como a indagação: homem ou mulher? Desse modo, Dias (2012) enfatiza que "A identidade do indivíduo como pertencente a um ou a outro sexo é feita no momento do nascimento, segundo o aspecto da genitália externa." Então, ao nascer, o indivíduo, de acordo com seu sexo morfológico, será considerado "masculino" ou "feminino". Assim, a heterossexualidade compulsória dividiu o mundo entre esses dois sexos, os quais foram culturalmente aceitos como "normais". Na heteronormatividade o único padrão de 
gênero aceito é aquele referente ao sexo biológico dos indivíduos. Nesse sentido, no entendimento de Butler (2003):

A coerência ou a unidade interna de qualquer dos gêneros, homem ou mulher, exigem, assim uma heterossexualidade estável e oposicional. Essa heterossexualidade institucional exige e produz, a um só tempo, a univocidade de cada um dos termos marcados pelo gênero que constituem o limite das possibilidades de gênero no interior do sistema de gênero binário oposicional. (p.45)

Para Bourdieu (2014) "a sexualidade, tal como a entendemos, é efetivamente uma invenção histórica, mas que se efetivou progressivamente à medida que se realizava o processo de diferenciação dos diversos campos e de suas lógicas específicas" (p. 144). A diversidade sexual existe e é um fato. Os comportamentos, práticas, vivências e orientações sexuais fogem do binarismo sexual biológico aceito em nossa sociedade. As características físicas exteriores dos indivíduos não determinam, pois, sua sexualidade efetiva. Nesse caso, no grupo LGBT, temos a transsexualidade, que é a rejeição do próprio sexo (gênero). Na contemporaneidade a diversidade está presente e é uma questão irrefutável, cuja inserção na sociedade está gradativamente sendo, se não aceita, pelo menos, respeitada e vem conquistando espaços. No mundo as lutas pela igualdade de gênero e pelo respeito à diversidade sexual, especialmente durante o último século e o início deste, tem se mostrado incessante.

\section{SEGMENTO LGBT}

O Brasil tem vivenciado momentos de avanços e retrocessos em relação às questões dos homossexuais. As lutas pelos direitos civis e a inclusão social desses indivíduos obteve conquistas capazes de despertar o interesse do mercado para esse nicho. A partir dos anos 1990, houve uma ampliação dos espaços de sociabilidade dos homossexuais caracterizando um mercado segmentado capaz de produzir novas expressões comerciais associadas a esse público (Simões \& Facchini, 2009), surgindo, assim, o segmento LGBT. De acordo com Reinaudo e Bacellar (2008) esse segmento é diferente dos demais por não ter uma característica física explícita e por não ser "simples de mensurar, e seu tamanho e potencial dependem da atitude dos homossexuais e da sociedade em relação a eles." (p. 71). Para esses autores, quando os homossexuais não aceitam e escondem sua orientação sexual da sociedade não podem ser considerados consumidores desse segmento.

O que atualmente se define como a segmentação de mercado gls é toda a atividade econômica focada nos consumidores homossexuais que aceitam com naturalidade sua orientação sexual, desejando consumir produtos e serviços direcionados ao seu estilo de vida. Inclui também, no Brasil, os simpatizantes da sigla, as pessoas afetiva ou ideologicamente próximas dos homossexuais que aceitam com naturalidade sua orientação sexual. (Reinaudo \& Bacellar, 2008, p.72). 
Nessa perspectiva o segmento LGBT, "seja no lazer, turismo, moda, artes ou entretenimento, surge no contexto maior dos avanços de cidadania, liberdade individual e pluralismo democrático que caracterizaram o final do século XX" (Trigo, 2009, p. 144). Conforme apontou, em reportagem, Sousa (2012), segundo pesquisa da in Search Tendências e Estudos de Mercado, estima-se que a população LGBT no Brasil é de 18 milhões de pessoas, das quais $78 \%$ possui cartão de crédito e gastam até $30 \%$ mais em consumo do que os heterossexuais. Entretanto, esse nicho ainda não é explorado como deveria. Regis Oliveira (2002) afirma que "Se o Brasil tomar a iniciativa de promover o turismo G\&L, estará contribuindo não apenas para aumentar a renda do país, mas também para acabar com a discriminação e o preconceito dos quais os homossexuais são vítimas em pleno século $X X I^{\prime \prime}$ (p. 36)

Com as recentes inovações tecnológicas, o uso incessante e facilitador das redes sociais da internet e da telefonia celular, as informações chegam em tempo real e atingem rapidamente seu objetivo. Nessa perspectiva, Daniela Mercury, cantora/bailarina, ícone da geração axé-music/samba reggae, embaixadora do Unicef, no início de 2013, postou fotos e frases, via celular, anunciando ao mundo que estava casada com uma mulher, que tinha uma relação homoafetiva, trazendo à tona a discussão acerca da questão dos direitos do segmento LGBT, da diversidade sexual e da homoafetividade. Os impactos advindos com a atitude da cantora foram imediatos. Nessa época de alta conectividade, notícias atravessam fronteiras, interligam comunidades diversas em novas combinações de espaço-tempo e identidade que tornam o mundo, em realidade e em experiência mais interconectado e, segundo Hall (2006) provocam uma:

[...] aceleração dos processos globais, de forma que se sente que o mundo é menor e as distâncias mais curtas, que os eventos em um determinado lugar têm um impacto imediato sobre as pessoas e lugares situados a uma grande distância. (p.69)

A atitude espontânea da cantora, que é uma figura pública, bem sucedida e militante de diversas causas, além de expor com mais liberdade sua orientação sexual, numa sequência temporal e atingindo o máximo de pessoas no tempo presente com efeitos profundos e imediatos por meio das redes de telecomunicação, via satélite, foi considerada como exemplo de resultado positivo para as pessoas - principalmente famosas - que temem revelar sua homossexualidade. Os benefícios advindos da postura de Daniela Mercury vão ao encontro do que Reinaudo e Bacellar (2008) denominaram como modelo positivo para o público gay: "Gays e lésbicas, em especial os mais jovens, sentem uma ânsia profunda de conhecer e idolatrar gays e lésbicas famosos, bem-sucedidos, bonitos e assumidos, que espelhem de forma positiva a orientação sexual de minorias" (Reinaudo \& Bacellar, 2008). 
Ao expor publicamente sua relação homoafetiva, Mercury quebrou padrões, oportunizou a visibilidade das minorias sexuais, trouxe à tona a luta de gays e lésbicas pelos direitos civis e contra a homofobia, ratificou as formas de expressão e vivência da conjugalidade de homossexuais em um momento em que a Comissão de Direitos Humanos da Câmara dos Deputados tentava aprovar o Projeto de Decreto Legislativo n. 234/2011, comumente chamado de projeto de "cura gay" que visava permitir que psicólogos oferecessem tratamento para curar a homossexualidade, gerando forte manifestação da sociedade por considerar tal projeto um retrocesso nas conquistas LGBT em pleno século XXI e como explica Diniz (2013):

Cura gay foi o nome dado às iniciativas para patologizar a homossexualidade, isto é, para descrevê-la como doença. Falsamente se pressupõe que a heterossexualidade seria a única sexualidade saudável, para daí se classificar as outras formas de vivência como anormais. 0 destino dos desviantes seria a clínica gay. Uns poucos psicólogos solitários sustentaram haver tratamento psíquico para a homossexualidade e reclamam ser cerceados em sua liberdade profissional. Ora, não há liberdade profissional para práticas discriminatórias ou charlatanices [...] (p.17).

\section{DECIFRANDO SIGLAS}

Por meio dessa visibilidade provocada pelos homossexuais e oportunizada pelas mídias das novas redes de comunicação, pessoas desde remotas cidades brasileiras tiveram conhecimento, de uma forma ou de outra, da realidade dessa comunidade, da existência ou surgimento de uma "nova" identidade, de suas lutas, conquistas, necessidades e principalmente da homofobia. Cada notícia a respeito do movimento de lésbicas e gays era precedida por letras que formavam siglas cujos significados foram assimilados e tornaram-se familiarizados do grande público.

Várias foram as siglas criadas para as designações das minorias sexuais. Atualmente a sigla utilizada para nomear a comunidade homossexual é Lésbicas, Gays, Bissexuais, Travestis, Transexuais e Transgêneros (LGBT), que é aceita no mundo todo.

Até os anos 2000 o termo comumente usado para denominar a comunidade homossexual como um todo era Gays, Lésbicas e Simpatizantes (GLS), mas por não contemplar as pessoas bissexuais, passou-se a utilizar a sigla Gays, Lésbicas, Bissexuais e Simpatizantes (GLBS). Logo após resolveu-se por Gays, Lésbicas, Bissexuais, Transexuais, Travestis e Transgêneros (GLBT). Em seguida veio Gays, Lésbicas, Bissexuais, Transexuais e Transgêneros (GLBTT). Também teve Gays, Lésbicas, Bissexuais, Travestis, Transexuais, Transgêneros e Simpatizantes (GLBTS). Finalmente, na Primeira Conferência Nacional de Gays, Lésbicas, Bissexuais, Travestis e Transexuais, realizada em Brasília em junho de 2008, foi aprovada a sigla atual LGBT. Segundo Simões e Facchini (2009) essa conferência, inédita, foi realizada como um reconhecimento do Governo da demanda do segmento. 
Na época, a própria comunidade homossexual ficou dividida quanto ao uso da letra "L", em referência às lésbicas, no início da sigla, cuja justificativa seria a de tentar dar maior visibilidade às reivindicações das mulheres, historicamente discriminadas. Mas prevaleceu a sigla LGBT por melhor representar essa comunidade, não obstante, no Brasil, no início dos anos 1990, GLS tenha sido a primeira sigla a dar nome ao, na época, recém-inaugurado segmento de mercado:

André Fischer, diretor-executivo do Grupo Mix Brasil e criador da sigla, conta que ela foi lançada em 1994, na primeira edição do Festival Mix Brasil de Cinema da Diversidade Sexual. "Observamos que o público não era formado apenas por gays e lésbicas, mas também por pessoas interessadas em cultura. Resolvemos chamar esse grupo de simpatizantes." (Fischer, 2009, como citado em Péret, 2011, p.84).

É certo que há polêmicas quanto ao uso das siglas que designam o segmento e que possam atender a todos, entretanto, atualmente as mais utilizadas são: LGBT e GLS, além do termo gay friendly. A primeira, para identificar todas as orientações sexuais (Lésbicas, Gays, Bissexuais, Travestis, Transexuais e Transgêneros) e manifestações de gênero em um contexto mais político, de luta pela igualdade de direitos, de cidadania e de gênero. A segunda (Gays, Lésbicas e Simpatizantes) para identificar o público que frequenta estabelecimentos como bares, restaurantes, boates, festas, destinados ao entretenimento não heterossexual, mas que recebe todo tipo de público. Já a terceira, gay friendly, é utilizada pelas empresas e por simpatizantes "amigos dos gays", "amigos da diversidade", e identifica ambientes comerciais e pessoas que respeitam e/ou aceitam a diversidade de gênero e a orientação sexual de seus consumidores, cujas posturas não excluem os homossexuais. Como afirma Seffener (2011):

Embora exista uma multiplicidade de produção de posições de sujeito no terreno do gênero e da sexualidade, no âmbito da luta política e do movimento social, as identidades fortes são apenas quatro: gay, lésbica, travesti e transexual. Grande parte das instituições da sociedade civil, em sua luta pela obtenção de direitos e pela conquista do reconhecimento e do respeito à diversidade, articula suas demandas em torno das quatro identidades. (p.43)

Até hoje é grande a confusão feita entre as siglas LGBT e GLS, as quais, apesar de serem parecidas, possuem diferenças fundamentais, conforme já apresentado. Na maioria das vezes todas as mídias e a literatura utilizam apenas a GLS tanto no sentido de identificação das várias orientações sexuais como para designar o público heterossexual que frequenta locais de entretenimento voltados para homossexuais.

\section{TURISMO LGBT EM BRASÍLIA}

A partir de pesquisas encomendadas por associações LGBT, Amorim e Vasconcelos (2012), em reportagem, afirmam que o consumidor homossexual apresenta maior disposição em gastar, em média, até $30 \%$ a mais que os heterossexuais com entretenimento, cultura, turismo e diversos bens 
de consumo. Possui um aguçado senso para o conforto e suas escolhas recaem, na maioria das vezes, por ambientes e lugares bem cuidados, confortáveis e que possuam um conceito interessante, aliados a um atendimento impecável. Ainda de acordo com a pesquisa acima referenciada, esse público geralmente não possui filhos e a renda de um casal homoafetivo é dobrada, considerando que não têm gastos idênticos ao de uma família tradicional. Viajam a lazer em média três vezes por ano, em qualquer período, para dentro e fora do país.

Nesse contexto, percebe-se que o segmento homossexual, abonado, é um dos que mais usufrui dessa prerrogativa de viajar utilizando-se de roteiros turísticos que atendam sua demanda, com destinos onde possa ser bem acolhido, inserido na sociedade local, sem formar guetos. Conforme Trigo (2009) "A conquista dos espaços gays na sociedade passou pelo mercado, sendo o setor de viagens e turismo para o público gay precedido pela expansão do entretenimento segmentado" (p. 149).

$\mathrm{Na}$ capital do Brasil, o universo LGBT, segundo informações divulgadas pelos jornalistas Vasconcelos e Amorim (2012), é majoritariamente formado por pessoas de poder aquisitivo e escolaridade superior à média dos demais habitantes, demonstra maior desejo por turismo, cultura e bens de consumo em geral. São informadas, vivem conectadas às redes sociais, são interessadas nos avanços políticos do segmento, nas questões culturais, sociais e ambientais. E, ainda conforme esses jornalistas, cerca de $70 \%$ da população gay do Distrito Federal pertence às classes A e B.

Conforme informações de Bonfanti (2011) parece haver uma tendência dos empresários brasilienses em investir no segmento de mercado para atender os homossexuais, na perspectiva da existência de uma demanda com poder de compra muito grande. Começaram a visualizar oportunidades de negócios nesse nicho de forma a atrair o que ficou conhecido como o pinkmoney. No entendimento de Bonfanti (2011) investidores ficaram atentos ao poder de consumo dessas pessoas não só para a diversão, o entretenimento, moda e beleza, mas, também, perceberam espaços poucos explorados para conquistar o segmento, como a dos setores da construção civil, decoração e turismo. Para cativar esse público, verificaram a necessidade de oferecer um atendimento com qualidade a um preço justo.

O Grupo LGBT de Brasília juntamente com a Secretaria de Cultura traçou um perfil do segmento a partir da amostragem de 600 pessoas entrevistadas. Conforme Lacerda e Bernardes (2013, p. 23), a comunidade LGBT do Distrito Federal é integrada por $59,7 \%$ de gays, $29,2 \%$ de lésbicas, 5,5\% de bissexuais femininas, 5,5\% de bissexuais masculinos, 0,8\% de travestis, $0,5 \%$ de transgêneros e $0,2 \%$ de transexuais. Quanto à classe econômica desse grupo $57 \%$ pertencia a classe "B", $26 \%$ a classe "C", $14,7 \%$ a classe "A", 2,2\% a classe " $D$ " e $0,2 \%$ a classe "E". No quesito 
escolaridade $27,7 \%$ tinham ensino médio completo, $21,8 \%$ ensino superior incompleto, $19 \%$ ensino superior completo, 13,5\% pós-graduação, $9 \%$ ensino médio incompleto, 7,2\% ensino fundamental completo e $1,8 \%$ ensino fundamental incompleto.

Em reportagem, Lacerda e Bernardes (2013) informaram que, a partir de pesquisa realizada em 2012 pelo grupo LGBT de Brasília e pela Secretaria de Cultura do DF com homossexuais da cidade, acerca da oferta do mercado local para atender o segmento, a maioria dos entrevistados se mostrou satisfeita com os estabelecimentos voltados para eles, embora, segundo esses autores, as alternativas atualmente existentes para esse público, em especial no setor de viagens e turismo, ainda, perdem para as cidades das regiões Sudeste (Rio de Janeiro, São Paulo), Sul (Florianópolis, Porto Alegre) e Nordeste (Salvador, Recife), de acordo com levantamento realizado pelo sociólogo Fabio Mariano, da consultoria InSearch Tendências e Estudos de Mercado (Lacerda \& Bernardes, 2013). Entretanto, devemos considerar que Brasília é uma cidade com apenas 55 anos de idade, bem mais jovem se comparada às urbes quatrocentonas como das outras regiões citadas, mas cujo comércio voltado para esse segmento ou considerado gay friendly, aparentemente, vem aumentando. Além de ser considerada a cidade mais tolerante da região Centro-Oeste. "O Brasil Central conserva características de um país colonial, com valores muito tradicionais. Brasília rompe discretamente com o pensamento arcaico" (Mariano, como citado em Lacerda \& Bernardes, 2013, p. 24).

Nessa perspectiva, Brasília é uma cidade que tende a ser considerada receptiva para homossexuais e nos últimos anos tem se mostrado atenta para a capacidade de consumo dessa clientela que é, reconhecidamente, exigente:

Nada anormal para uma capital que se mostra cada vez mais tolerante com a pluralidade da população. O Censo de 2010 não deixa dúvidas. O DF foi a segunda unidade da Federação com mais casais que se declaram homoafetivos. São 1.230 pessoas, representando $0,048 \%$ da população local, atrás somente do Rio de Janeiro (Rios, 2012, p.29).

Com uma maior exposição das mídias relativa às conquistas e potencial de consumo dos homossexuais e da possibilidade de obtenção de lucros com esse público, tanto empresários quanto - Governo local "se mostram dispostos a investir em treinamento especializado para esse público" (Amorim \& Vasconcelos, 2012, p. 18). A visibilidade do movimento LGBT em Brasília poderá desencadear investimentos no setor de consumo de bens, viagens, lazer, serviços, turismo entre outros, visando satisfazer e atrair a clientela do segmento local e externo.

Segundo informação pessoal de servidores do Ministério de Turismo e durante o "Simpósio Turismo Responsável nos Destinos - Brasil 2014" realizado no Centro de Excelência em Turismo da Universidade de Brasília, o Ministério do Turismo está desenvolvendo uma cartilha de construção da 
cidadania, no sentido de promover o turismo como um fator de inclusão social, contemplando o segmento LGBT no que diz respeito a ações como apoio à comercialização e estruturação de produtos além de treinamento e qualificação das pessoas que atendem diretamente esse público.

O mercado de eventos para homossexuais em Brasília possui maior concentração de equipamentos de lazer e socialização nas áreas do Plano Piloto, onde a renda per capita costuma ser superior ao das cidades satélites, além de possuir uma sociedade considerada mais tolerante, talvez em decorrência da pluralidade da população.

A comunidade LGBT, ao contrário do imaginário de grande parte da população, não gasta só com entretenimentos da cena noturna (principalmente baladas). É uma ávida consumidora de atrativos culturais, turismo, decoração, moda e beleza (Vasconcelos \& Amorim, 2012). Não costuma frequentar somente os locais específicos para seus pares, aqueles onde podem expressar livremente sua orientação sexual, os denominados "guetos gays". Prefere lugares onde predomina o respeito à diversidade, espaços mais democráticos.

O mercado desse segmento tende a crescer. Dentro do contexto de alcançar a satisfação desse público, cada vez mais visível e numeroso, é que se encontra a cidade de Brasília, a capital monumento, a qual parece despontar como um polo de turismo e de entretenimento, com possibilidades de seduzir gays e lésbicas. Há indícios de que hotéis, restaurantes, bares, festas, comércio e parques ecológicos estariam dispostos a receber essas pessoas e, por meio de ações eficazes, viriam a contribuir para um ambiente acolhedor. O retorno desses indivíduos aos locais ocorrerá sempre que houver receptividade e atendimento às demandas.

Com relação ao turismo voltado para a comunidade homossexual, Brasília vem aos poucos se preparando para acolher esse tipo de turista, conforme demonstra a mídia impressa da cidade, já citada. Recentemente foi divulgado que a EMBRATUR (Instituto Brasileiro de Turismo) começará a divulgar a cidade como receptiva para o público LGBT (Bittar, 2015), a capital do país entraria no circuito das cidades brasileiras consideradas gay friendly, mas esse Instituto enfatiza a necessidade de melhorar a mão de obra para atender esse público. Em 2010 a revista Via G já apresentava a cidade como um polo de turismo para a diversidade "A capital se firma como grande pólo de turismo tornando-se destino obrigatório do circuito LGBT no país" (Lucas, 2010).

Com o crescimento do mercado LGBT, os turistas homossexuais na Capital da República poderão exigir mais respeito, qualidade e serviços adequados às suas necessidades e se voltarão prioritariamente para empresas cuja postura seja claramente favorável à diversidade sexual e aos espaços mais tolerantes. É certo que ainda há muito por fazer pelo movimento de lésbicas e gays, principalmente no que diz respeito à conjugalidade, mas como observa Castells (2002): “[...] se a 
experiência vivenciada no último quarto de século tiver algum valor indicativo para o futuro, o poder da identidade se reveste de mágica quando tocado pelo poder do amor."

Nessa perspectiva, acredita-se que as mudanças ocorridas e as que estão por vir, tendem a favorecer a comunidade LGBT que aos poucos vai transformando o olhar social em busca de um maior acolhimento de sua identidade sexual e rompendo padrões socioculturais considerados estáveis.

O turismo LGBT no Brasil começou a ser visto como um nicho a partir das conquistas alcançadas pela comunidade homossexual, nos últimos anos do século $\mathrm{XX}$, as quais oportunizaram a visibilidade para essas pessoas. A partir dessa visibilidade, o que antes era visto com muitas ressalvas e receio pelo mercado, passou a ser uma oportunidade de negócios.

Nesse aspecto, Brasília que sempre atraiu turistas, mais em função de sua arquitetura, turismo de negócios e cívico, começa a despontar no sentido de investir na e para a comunidade LGBT. A mídia vem divulgando, nos últimos anos, o interesse demonstrado por empresários e até pelo Governo Federal e Local em investir na melhoria do atendimento dessas pessoas, por considerar essa cidade aberta à diversidade.

\section{REFERÊNCIAS}

Amorim, D. \& Vasconcelos, B. (2012). Atenção especial ao mercado gay. Correio Braziliense, Brasília, 26 nov. 2012. Caderno Cidades, Economia no DF, p. 30.

Bittar, B. (2015). Brasília destino gay-friendly. Correio Braziliense, Brasília, 13 jan. 2015. Caderno Cidades. 24.

Bonfanti, C. (2011). Gays fazem a economia girar. Correio Braziliense, Brasília, 22 mar. 2011. Caderno Economia, p.19.

Bourdieu, P. (2014). A dominação masculina: a condição feminina e a violência simbólica. Rio de Janeiro: Best Seller.

Butler, J. (2003). Problemas de gênero: feminismo e subversão da identidade. Rio de Janeiro: Civilização Brasileira.

Campbell, U. (2014). Território livre. Veja, Brasília, Brasília, 19 fev. 2014. Comportamento, p. 29.

Castells, M. (1999). O poder da identidade. 3. ed. São Paulo: Paz e Terra. v. 2.

Contaifer, J. (2014). Existe turismo na capital? Correio Braziliense, Brasília, 16 mar. 2014. Revista do Correio, 26-27.

Dias, M. B. (2004). Conversando sobre homoafetividade. Porto Alegre: Livraria do Advogado.

tribunais.

(2012). União homoafetiva: o preconceito \& a justiça. 5. ed. São Paulo: Revista dos

Diniz, D. (2013). Cura gay. Correio Braziliense, Brasília, 22 jun. 2013. Opinião, p. 17.

Foucault, M. (2007). História da sexualidade: a vontade de saber. 18. ed. São Paulo: Graal, v. 1. 
Guerra, A. (2002). Turismo homossexual no Brasil: um segmento em expansão. 2002. 58 f. Monografia (Lato Sensu) - Centro de Excelência em Turismo, Universidade de Brasília, Brasília.

(2013). Conjugalidade, parentalidade, regulação da cidadania e direitos humanos de lésbicas, gays e transgêneros no Brasil. Cenário - Centro de Excelência em Turismo da Universidade de Brasília, v. 1, n.1 (2013) - Brasília.

Hall, S. (2006) A identidade cultural na pós-modernidade. 11. ed. Rio de Janeiro: DP\&A.

Krippendorf, J. (2001). Sociologia do turismo: para uma nova compreensão do lazer e das viagens. 3. ed. São Paulo: Aleph.

Lacerda, M. \& Bernardes, A. (2013). Diversão em todas as cores. Correio Braziliense, Brasília, 09 jun. 2013. Caderno Cidades + Política e Economia no DF, 23.

Lacerda, M. \& Bernardes, A. (2013). Mercado caro em ascensão. Correio Braziliense, Brasília, 09 jun. 2013. Caderno Cidades, 24.

Lucas, T. (2010). Brasília muito mais diversidade. Via G. São Paulo: Via G Ltda.

Moesch, M. (2002). A produção do saber turístico. São Paulo: Contexto.

Molina, S. (2005). Turismo metodologia e planejamento. Bauru: Edusc.

Mott, L. (2003). Crônicas de um gay assumido. Rio de Janeiro: Record.

Oliveira, L. (2002). Turismo para gays e lésbicas: uma viagem reflexiva. São Paulo: Roca.

Oliveira, R. (2013). Homossexualidade: análises mitológica, religiosa, filosófica e jurídica. 2. ed. São Paulo: Revista dos Tribunais.

Platão. (1999). O banquete: ou do amor. 9. ed. Rio de Janeiro: Bertrand Brasil.

Prado, M. \& Machado, F. (2008). Preconceito contra a homossexualidades: a hierarquia da invisibilidade. São Paulo: Cortaz.

Péret, F. (2011). Imprensa gay no Brasil: entre a militância e o consumo. São Paulo: Publifolha.

Reinaudo, F. \& Bacellar, L. (2008). O mercado gls: como obter sucesso com o segmento de maior potencial da atualidade. São Paulo: Ideia\&Ação.

Rios, M. (2012). As cores do arco-íris. Correio Braziliense, Brasília, 21 abr. 2012. Caderno Especial Brasília 52 anos, 29.

Seffner, F. (2011). Identidade de gênero, orientação sexual e vulnerabilidade social: pensando algumas situações brasileiras. In: VENTURI, Gustavo; BOKANY, Vilma (Org.). Diversidade sexual e homofobia no Brasil. São Paulo: Fundação Perseu Abramo. p. 38-50.

Silva Junior, A. M. (2014). Diversidade sexual e inclusão social: uma tarefa a ser completada. Franca: Lmeos e Cruz.

Simões, J. \& Facchini, R. (2009). Na trilha do arco-íris: do movimento homossexual ao LGBT. São Paulo: Fundação Perseu Abramo.

Sousa, I. (2012). Mercado é cego para potencial de consumo do público LGBT. Exame.com. Disponível em: <http://exame.abril.com.br/marketing/noticias/mercado-e-cego-para-potencial-de-consumodo-publico-lgbt>. Acesso em: 19 fev. 2015.

Trevisan, J. (2006). Turismo e orientação sexual. In: BRASIL. Ministério do Turismo (Org). Turismo social: diálogos do turismo, uma viagem de inclusão. Rio de Janeiro: IBAM, p.139-177. 
Trigo, L. (2009). Ascensão do prazer na sociedade atual: turismo GLS. In: NETTO, Alexandre Panosso; ANSARAH, Marília Gomes dos Reis (Org.). Segmentação do mercado turístico: estudos, produtos e perspectivas. Barueri: Manole, p.141-163.

Vasconcelos, B. \& Amorim, D. (2012). A força do consumo gay. Correio Braziliense, Brasília, 25 nov. 2012. Caderno Cidades + Política e Economia no DF, p. 29.

Vasconcelos, B \& Amorim, D. (2012). Cena LGBT impulsiona lucro. Correio Braziliense, Brasília, 25 nov. 2012. Caderno Cidades, p. 31. 